\title{
X-ray microtomography to evaluate the efficacy of paraffin wax coating for soil bulk density evaluation
}

\author{
Luiz F. Pires ${ }^{a}$, Sacha J. Mooney ${ }^{b}$, André C. Aulera, Brian Atkinsonn, Craig J. \\ Sturrock ${ }^{b}$ \\ a Laboratory of Physics Applied to Soils and Environmental Sciences, Department of Physics, \\ State University of Ponta Grossa (UEPG), 84.030-900, Ponta Grossa, PR, Brazil \\ b Division of Agricultural and Environmental Sciences, School of Biosciences, University of \\ Nottingham, Sutton Bonington Campus, Leicestershire LE12 5RD, UK
}

Corresponding author:

Prof. Dr. Luiz F. Pires, Phone: (55) 42-3220-3044. Fax: (55) 42-3220-3042. E-mail: Ifpires@uepg.br (L.F. Pires)

Prof. Dr. Sacha J. Mooney. E-mail: sacha.mooney@nottingham.ac.uk

Proofs should be sent to:

Dr. Luiz Fernando Pires, Departamento de Física, Universidade Estadual de Ponta Grossa, Campus de Uvaranas, Bloco L, Sala 15B; Av. Carlos Cavalcanti, 4748, CEP 84.030-900, Ponta Grossa, PR, Brazil. 


\title{
X-ray microtomography to evaluate the
}

\section{efficacy of paraffin wax coating for soil bulk}

\section{density evaluation}

\author{
L.F. Pires ${ }^{a, 1}$, S.J. Mooney ${ }^{b, 1}$, A.C. Aulera, B. Atkinson ${ }^{b}$, C.J. Sturrock ${ }^{b}$ \\ a Laboratory of Physics Applied to Soils and Environmental Sciences, Department of Physics, \\ State University of Ponta Grossa (UEPG), 84.030-900, Ponta Grossa, PR, Brazil \\ b Division of Agricultural and Environmental Sciences, School of Biosciences, University of \\ Nottingham, Sutton Bonington Campus, Leicestershire LE12 5RD, UK
}

\section{ABSTRACT}

The paraffin-coated method is a well used approach to measure the soil bulk density (BD). BD is a physical property of great importance for studies of soil quality and health.

Therefore, representative measurements of this property are highly valued. Resin and paraffin wax are utilized to coat soil samples however; if these materials ingress into the sample it could affect the representativeness of BD evaluation. The advance in threedimensional (3D) image analysis techniques such as X-ray microtomography $(\mu C T)$ offers a great opportunity to visualize and quantify the possible penetration of paraffin wax into clod samples. In this paper we investigated porous system morphological properties of soil samples coated with paraffin wax. The morphological properties of the pores filled with paraffin wax inside the samples were also studied. We observed qualitatively that samples with large pores close to their borders were more susceptible to the penetration of paraffin wax. Samples with pores $>10 \mathrm{~mm}^{3}$ had the highest amount

\footnotetext{
${ }^{1}$ Corresponding authors.

Tel.: +55 42 3220-3044; Fax: +55 42 3220-3042

E-mail addresses: Ifpires@uepg.br (LF Pires); sacha.mooney@nottingham.ac.uk (SJ Mooney)
} 
of paraffin wax into them. Triaxial shaped and complexly pores also offered less resistance to the ingress of paraffin wax. Positive relations between the amount of paraffin wax inside the samples and the volume of pores measured, pore tortuosity and degree of anisotropy were found. Conversely, the soil pore connectivity was not correlated with the penetration of paraffin wax into the samples, at least for the region of interest $\left(\approx 27.3 \mathrm{~cm}^{3}\right)$ studied. Finally, an analysis of the impact of paraffin wax ingress inside the samples in measured BD showed increments of $\approx 0.09$ and $\approx 0.11 \mathrm{~g} \mathrm{~cm}^{-3}$ in this property when the paraffin wax penetrates into the large pores.

Keywords: X-ray Computed Tomography; Soil porous system; Connectivity; Tortuosity; Soil bulk density.

\section{Introduction}

Soil bulk density (BD) represents an important physical property obtained by the ratio of mass of solids to the total sample volume. This soil property can be measured by several different methods in wet and dry samples (Hillel, 2004). Soil bulk density is commonly utilized as an index of soil quality and health (Gantzer and Anderson, 2002; Hakansson and Lipiec, 2000), used to convert between weight and volume of soil, and also for water content and soil porosity or pore volumes (Hillel, 2004), and a widely accepted property for referring to the compactness of a soil (Lal and Shukla, 2004).

There are several methods employed to measure BD as described by Grossman and Reinsch (2002) and Shipp and Matelski (1965). The most traditional is the core method, which makes use of cylinders to collect the samples. Timm et al. (2005) and Pires et al. (2011) present a discussion about nuclear and traditional methods for measuring BD. According to these authors, each method has their own particularities and the choice of one over the others depends on several factors, such as, for example, site characteristics, time, laboratory or field measurements and costs.

The paraffin-coated method is another common traditional methodology for measurement of BD (Auler et al., 2017; Grossman and Reinsch, 2002). In this method 
50 the volume of the samples is determined by coating them with a water-repellent

51 substance. Normally, paraffin wax is used due to its low cost and easiness to work with

52 (Holden, 1994). However, the technique is prone to error if the paraffin wax penetrates

53 the pores within the soil sample rather than simply coating its surface (Rossi et al., 2008;

54 Grossman and Reinsch, 2002). In routine measurement, the identification of the paraffin wax penetration inside the clods is not easy and, probably, errors in the measurement of BD through the paraffin-coated method do occur but are unquantifiable. If paraffin does ingress into a soil sample, the impact on measurement of BD by this method could be significant.

According to van Remortel and Shields (1993), the ingress of paraffin wax into soil clods can reduce their measured volume and, consequently, it results in a higher BD (Solgi et al., 2018). For very gravely soils, Hirmas and Furquim (2006) observed that when the paraffin wax is absorbed deep into clods, problems to remove the soil and wax coatings on the gravel tend to inflate the mass of gravel. Therefore, the mass of gravel in clod samples is overestimated increasing BD (Rossi et al., 2008).

Methods of image analysis such as X-ray Computed Tomography (CT), which is based on the attenuation of the radiation by materials of different densities (Pires, 2018), can assess the internal structure of soil samples and potentially quantify the penetration of paraffin wax. Since the development of the X-ray CT in the early seventies of the last century (Hounsfield, 1973), many applications of this technique have been applied across different research areas, where the aim was to study the internal structure of porous media (Ferreira et al., 2018; Carducci et al., 2017; Cnudde and Boone, 2013; Mooney et al., 2012; Vaz et al. 2011; Pires et al., 2010; Crestana et al., 1985). The combination of the X-ray CT data and image analysis programs permits a detailed 3D characterization of the soil porous system (Grayling et al., 2018; Tseng et al., 2018; 
measurements such as pore volume, shape, orientation, continuity, tortuosity and macropore size distribution can be obtained from X-ray CT images.

No previous study has sought to quantify the potential ingress of paraffin wax inside soil samples. The objective of this study was to investigate the possibility of paraffin wax penetration inside soil samples and to study the effect of the pore morphological properties on the amount and distribution of paraffin wax within the samples. These objectives were achieved through 3D X-ray CT analysis of samples coated with paraffin wax at the resolution scale of mesopores and macropores.

\section{Materials and methods}

\subsection{Sample characteristics and preparation}

Samples were collected from the experimental farm of the Agricultural Research Institute of Parana (IAPAR) in the city of Ponta Grossa, PR, Brazil (2506'S, $50^{\circ} 10^{\prime} \mathrm{W}$, $875 \mathrm{~m}$ above sea level). The soil under investigation was an Oxisol (Rhodic Hapludox), according to USDA soil taxonomy (Soil Survey Staff, 2013), of clay texture (17\% sand, $22 \%$ silt, and $61 \%$ clay).

Three sets of samples were collected for this study: Group 1 - samples with volumes between 50 and $100 \mathrm{~cm}^{3}$, which were utilized for BD measurement by the paraffin-coated method ( $\mathrm{n}=8$ samples); Group 2 - samples with volumes between 90 and $97 \mathrm{~cm}^{3}$, which were utilized for BD measurement by the core and paraffin-coated methods ( $n=14$ samples); and Group 3 - samples with volumes ranging from 70 to 75 $\mathrm{cm}^{3}$, which were employed for the image analysis ( $\mathrm{n}=36$ samples). All the samples were manually collected at the soil surface $(0-10 \mathrm{~cm})$ with the help of an Uhland sampler (core method - stainless steel cylinders with height of $\approx 5.0 \mathrm{~cm}$ and internal diameter of $\approx 4.8$ $\mathrm{cm}$ ) and shovel and trowel (clod method). Samples of groups 1 and 2 were collected in August 2018 and of group 3 in April 2017. An area of about 3.0 to 3.0 m under minimum tillage was selected to collect the samples near the center of the experimental plot $(50 \times$ 
$120 \mathrm{~m}$ ) for groups 1 to 3 . A distance of around 20 to $30 \mathrm{~cm}$ was kept between samples throughout the sampling procedures, which were carried out after harvest (normally ryegrass - Lolium multiflorium).

The samples of group 1 were selected to measure the impact of the paraffin wax ingress in direct measurements of BD by the paraffin-coated method, while the samples of group 2 were chosen to show the differences in BD before and after coating with paraffin wax. The samples of group 2 were carefully removed from the cylinders prior the coating procedure. These samples were also analyzed to identify possible differences in BD caused by soil spatial variability, instead by the paraffin wax penetration. The ingress of paraffin wax into the samples of groups 1 and 2 was verified based on visual examination after disintegrating the samples (Fig. 1d). Finally, samples of group 3, which were also carefully extracted from cylinders, were analyzed to investigate, through image analysis, the effect of pore morphological properties on the amount and distribution of paraffin wax inside the soil samples. Prior to X-ray CT scanning, samples were dried at $40^{\circ} \mathrm{C}$ until their mass became constant, in order to eliminate as much of the water phase as possible from the samples (Jefferies et al., 2014).

For the impregnation of the samples, hard paraffin wax was kept in a container and melted until air bubbles were no longer observed. The temperature was controlled with a digital LCD thermometer (Figs. 1a,b). Carefully a piece of thread (nylon string) was tied around the sample, leaving about $15 \mathrm{~cm}$ free. Holding onto the end of the free thread, the sample was momentarily dipped in the melted paraffin wax. The excess of paraffin wax was allowed to drain after the previous step. The next step was to wait for the adhering paraffin wax to solidify ( 10 minutes). This procedure was carried out individually for each soil sample studied.

The BD measurement by the core method was made following the procedures described in Grossman and Reinsch (2002). For the paraffin-coated method, first the weight of the soil clod $\left(\mathrm{W}_{1}\right)$ was measured in air and again after coating with paraffin wax 
$129\left(\mathrm{~W}_{2}\right)$. The weight of paraffin-wax used in coating was obtained by the difference between

$130 W_{2}$ and $W_{1}$. The total clod volume coated with paraffin wax $\left(V_{t}\right)$ was measured after 131 weighting the clod submerged in water. The volume of paraffin wax utilized in coating $132\left(\mathrm{~V}_{\mathrm{pa}}\right)$ was determined using the weight of paraffin wax employed in coating and its density $133\left(0.90 \mathrm{~g} \mathrm{~cm}^{-3}\right)$. Finally, the actual volume of soil $\left(\mathrm{V}_{\mathrm{s}}\right)$ was calculated by the difference 134 between $V_{t}$ and $V_{p a}$, and, $B D$ as the ratio of $W_{1}$ and $V_{s}$.

\subsection{X-ray Computed Tomography}

Each soil sample was scanned using a GE v|tome|x m X-ray CT scanner (GE Measurement \& Control Solutions, Wunstorf, Germany) at the Hounsfield Facility (The University of Nottingham, Sutton Bonington Campus, UK). The voltage, current and integration time adopted for the image acquisition process were $180 \mathrm{kV}, 160 \mu \mathrm{A}$ and 250 ms. A $0.1 \mathrm{~mm}$ Cu-filter was used to minimize beam-hardening effects. A total of 2520 projections were obtained per sample with a pixel resolution of $35 \mu \mathrm{m}$. Therefore, it was not possible to resolve pores below this resolution.

\subsection{Image reconstruction, processing and analysis}

The radiographs of each scan were reconstructed in 32 bit format in order to avoid compression of the greyscale histogram. After reconstruction the images were imported into Volumetric Graphics (VG) StudioMAX® 2.0 and after into ImageJ 1.42 and cropped to a cubic shape with $30.1 \times 30.1 \times 30.1 \mathrm{~mm}^{3}(860 \times 860 \times 860$ pixels $)$.

The main objective of the image analysis was the verification of the possibility of paraffin wax penetration into the soil samples after the coating procedure. After that, some morphological properties of the soil porous system was measured with an aim to evaluate the influence of them in the paraffin wax penetration into the samples. The choice of a region of interest smaller than the whole soil sample imaged was based on the time needed for each image analysis (several days) and the computational work. The amount of computer system memory (64 GB RAM) allocated for the analyses allowed 
only to work with samples of size similar to the region of interest selected. The complexity of the soil porous system and the number of parameters studied influenced the amount of memory necessary for the measurements. However, the volume of the samples (region of interest) analyzed were selected close to the borders of them. This was made due to the importance of the pores next to the sample surface to the entrance of paraffin wax. However, we believe that the use of special masks (image analysis procedures) and powerful computers can allow the future analysis of entire and big volumes for a better characterization of the soil porous system and it susceptibility to the paraffin wax ingress.

A preliminary analysis revealed that 27 of the 36 samples had negligible paraffin wax ingression. As such no further analysis was conducted on these samples. A full morphological characterization was subsequently performed on the remaining nine samples $(25 \%)$ for the region of interest selected. So, we decided to call these samples in the text as S1 to S9.

The original grey-level X-ray CT images were processed using ImageJ 1.42 software (Rasband, 2007). The segmentation process was based on the nonparametric and unsupervised Otsu method of threshold (Otsu, 1979). The images were also visually inspected to verify the quality of the segmentation procedure. This resulted in a binary image, in which pores and soil material were respectively represented by white and black pixels. A third peak was also observed in the image cross sections, which was related to the paraffin wax (Fig. 2). The threshold value defined based on the Otsu method was the same for all the cross sections of a same sample. To segment the paraffin wax only by the Otsu method, image tools such as subtract background (radius 350 pixels), enhance contrast $(0.5 \%)$, remove outliers (radius 0.7 pixels) and median 3D filters (radius 2.0 pixels) were utilized. After this procedure a binary image of the pores filled with paraffin wax in black and the solid phase in white pixels was obtained. In these images, pores not filled with paraffin were disregarded. 
For the 3D structural assessment, soil pores were classified according to their size and shape distribution. For the shape classification, geometrical parameters known as major, intermediate and minor axes of the ellipsoids that represent each pore were determined by using 3D measuring techniques (Schmitt et al., 2016; Bullock et al., 1985). These parameters were measured using the Particle Analyser tool in ImageJ. Binary images of the whole soil porous system and the pores filled only with paraffin wax were utilized in these measurements. Isolated pores $<9$ voxels were removed from the porous fraction of the images in the quantitative analyses to avoid misclassification from unresolved voxels (Jefferies et al., 2014). The soil pores which allowed the measurement of the three principal axes were classified according to the terminology suggested by Zingg (1935). The relation between the ratio of the intermediate by the major (Int./Maj.) axis and the ratio of the minor by the intermediate (Min./Int.) axis allows the classification of pores based on shape. Therefore, the pores were classified as: Equant (EQ), Prolate (PR), Oblate (OB), and Triaxial (TR) (Pires et al., 2017). When one of the axes of a specific pore could not be determined, this pore was not classified (unclassified pore) according to its shape. These pores are associated enhanced complexity of individual pores, which means that a geometrical shape cannot be fitted for them.

The porosity (P) and number of pores (NP) were calculated taking into consideration the resolvable pores. In this study the term porosity refers to the sum of mesopores and macropores based on the size classification of Brewer (1964). The pore size distribution (sorted by pore volume) corresponded to the total number of disconnected pore volumes inside the sample. For P and NP size distribution analysis, pores were classified in different volume intervals: $0.0001-0.01 ; 0.01-0.1 ; 0.1-1 ; 1-10$; and $>10 \mathrm{~mm}^{3}$. These volume intervals were selected based on the importance of different pore sizes in the water infiltration, redistribution, retention and root penetration, for instance. 
The X-ray CT images were also analyzed in terms of network tortuosity $(\mathrm{T})$ and connectivity of the pores using the Osteoimage software (Roque et al., 2009). The tortuosity, which is geometrically defined by the ratio between the geodesic distance between two connected points and the Euclidian distance between these two points, was calculated through the geodesic reconstruction algorithm (Roque et al., 2012a,b). The Characteristic of Euler-Poincaré (EPC) was utilized to estimate the degree of connectivity, which represents one of the Minkowski functions and a topological measure used for describing the connectivity of spatial structures (Katuwal et al., 2015). EPC per sample volume was obtained considering 859 disectors, which represent contiguous image sections. EPC was estimated based on the algorithm discussed in Vogel and Kretzshmar (1996) from a set of sequential 2D registered images by the use of the dissector, which consists of two parallel sections a small distance apart. The dissector displacement in our case studies was $0.035 \mathrm{~mm}$, thus pores that lay in between the image slices could not be considered as they did not contribute according to the morphological operations (erosion and dilation by one pixel) implemented in the algorithm for the stereological procedures, which eliminates pores lesser than $\approx 0.0007$ $\mathrm{mm}^{3}$. Therefore, a sizeable volume of the isolated pores is not considered by this approach. In our study the volumetric $\mathrm{EPC}\left(\mathrm{EPC}_{\mathrm{V}}=E P C / \mathrm{V}\right)$, i.e., by the volume of dissectors, was determined after the images had been previously submitted to the Purify procedure in Bone J plugin (Odgaard and Gundersen, 1993; Toriwaki and Yonekura, 2002). The EPC $v$ number is an indicator of how well connected is a pore: the smaller (more negative) it is, the higher is the pore connectivity (Chappard et al., 1999; Roque et al., 2009).

The Euler Number (EN) was also utilized to evaluate the connectivity of pores larger than $0.2 \mathrm{~mm}^{3}\left(\mathrm{EN}_{>0.2}\right)$ and the largest pore $\left(E N_{B}\right)$ found. $E N$ was evaluated using the Particle Analyser and Bone $\mathrm{J}$ plugins in ImageJ, which allowed the analysis of connectivity of individual pores of different volumes (Doube et al., 2010). Prior the EN 
analyses, the image stacks were also submitted to the Purify procedure in Bone $\mathrm{J}$ plugin as done for $E P C_{V}$.

Parameters such as porosity, number of pores, and pore volume (PV) were also obtained for pores larger than $0.2 \mathrm{~mm}^{3}$. This analysis was carried out for the whole soil porous architecture and for the pores filled only with paraffin wax. The degree of anisotropy (DA), which gives the preferred orientation of pores, was also determined in 3D by using the Bone $\mathrm{J}$ plugin.

Statistical analyses were performed with the Past program (Hammer et al., 2001). Pearson correlations among each pair of variables were measured for the entire set of morphological parameters. The t-test $(p \leq 0.05)$ was used to compare the effect of paraffin wax ingress in $\mathrm{BD}$ measurements.

\section{Results and discussion}

\subsection{Image analysis}

3D images of the sample S8 are shown in Fig. 2. It is possible to observe in the images the penetration of paraffin wax inside the sample due to the procedure of coating. A qualitative analysis of the images also demonstrates that the largest pores at the sample surface were filled with paraffin wax, which is expected due to the reduced energy, solid-liquid contact angles, required to fill these pores (Jury and Horton, 2004; Or and Wraith, 2002).

Some authors have reported that the materials (resin or paraffin wax) utilized to coat the samples may not adequately seal the deepest pores, which can allow water penetration into them, affecting the measurement of their volumes (Sander and Gerke, 2007). On the other hand, the complete coating of soil samples with these characteristics could lead to the resin/paraffin penetration into them, as observed in our study. In addition to the influence of resin/paraffin entrance into the samples in the measurement of $\mathrm{BD}$, this problem can also influence the measurement of other physical properties 
261

262

263

264

265

266

267

268

269

270

271

272

273

274

275

276

277

278

279

280

281

282

283

284

285

286

287

such as water content and shrinkage curve measurements (Stewart et al., 2012; Schafer and Singer, 1976).

\subsection{Morphological physical properties}

Sample S6 was characterized by the smallest porosity and pore volume ( $P$ : 10.9\% and PV: 2976) and S8 by the highest (P: 23.7\% and PV: 6452), which indicates the relative variability (CV: $24.8 \%$ and $\mathrm{Cl}: 3.0$ for $\mathrm{P}$; $\mathrm{CV}: 25.8 \%$ and $\mathrm{Cl}: 846$ for $\mathrm{PV}$ ) of these properties among samples (Figs. 3a,b). The terms CV and Cl stand for coefficient of variation and confidence interval (95\%), respectively. In terms of NP (Fig. 3c), the smallest value was for S3 (50921) and the highest for S4 (68774). In general, the samples with the highest $\mathrm{P}$ and $\mathrm{PV}$ had the largest volume of paraffin wax inside them (Table 1) and they were characterized by the presence of larger pores $\left(N P_{>0.2}\right)$, which had a great contribution to P (Fig. 4a and Table 2).

The volumetric Euler-Poincare Characteristic (Fig. 3d), a measurement of the connectivity of the pores (Chappard et al., 1999), was lower for S7 $\left(-0.0118 \mathrm{~mm}^{-3}\right)$ and higher for S6 $\left(-0.0030 \mathrm{~mm}^{-3}\right)$. As discussed earlier the smaller $\mathrm{EPC}_{\mathrm{V}}$, the higher the pore connectivity (Roque et al., 2009). The pore size distribution analysis (Fig. 4a) showed that large pores contributed to more than $90 \%$ of $P$ (Table 2). For example, the samples with the largest proportion of paraffin wax inside them (S5, S8, S9) had more than $82 \%$ of their pores $>0.2 \mathrm{~mm}^{3}$ filled with paraffin (Tables 3 and 4). Therefore, the Euler Number, a measure of the degree of fragmentation of the pore networks (Schmitt et al., 2016), was undertaken for pores $>0.2 \mathrm{~mm}^{3}$ (Table 2). The pore network was less connected for S6 (-92183) and high connected for S1 (-248844). As observed for EPC $v(r=0.31)$, there was no significant relation between the pore connectivity results and the amount of paraffin wax inside the samples (Table 1). The presence of main, connected pore networks would be expected to contribute to a more effective flow path, but this was not observed in terms of paraffin wax penetration inside the samples for the region of interest studied (Rezanezhad et al., 2009). Differences in the chemical-physical properties of the 
paraffin wax (for example, surface tension, density, viscosity) in comparison to water and the presence of small pores connecting parts of the main pore network might account for this unexpected result (Lal and Shukla, 2004; Hillel, 2004; Turner et al., 1955). The possibility of the analysis of the whole sample studied, which means to characterize the pores in the border of the samples, could complement the results obtained and, perhaps show some different relation between the amount of paraffin wax and connectivity. However, it was not possible to analyze in our study the morphological properties of the entire sample as earlier discussed.

The smallest tortuosity was measured for S6 (1.05) and the highest for S8 (1.14) (Fig. 3e). High values of $\mathrm{T}$ are normally related to a more disconnected network (Rezanezhad et al., 2009). Samples with the largest amount of paraffin (S5, S8, S9) were also those with the largest $\mathrm{T}$ (Tables 1 and 3). However, the small values of $\mathrm{T}$ indicate that there was no significant fragmentation of the mesopores and macropores, which is in line mainly with the results of $\mathrm{EN}_{>0.2}$ (Katuwal et al., 2015; Pagenkemper et al., 2014). The degree of anisotropy results indicate an isotropic soil porous system (Fig. 3f). Small values of DA, close to 0 , suggest a soil porous system that is isotropic and water infiltration tends to be vertical. Values close to 1 suggest that the soil porous system is anisotropic and water infiltration can occur parallel to the soil surface (Tseng et al., 2018). The smallest DA value was in S4 (0.08) and the highest for S1 (0.27). In general, the samples with the largest amount of paraffin wax inside them were also those with the highest DA values (Table 1). However, the DA results should be used with caution in our work because the soil dipped into the melted paraffin wax is subjected to flow from different directions. The idea behind these results was try to find some relation between the isotropy of the soil porous system and the possibility of paraffin wax ingress into the samples.

\subsection{Pore size and shape distribution (whole porous system)}



porous space occupied with paraffin wax are presented in Table 3. Samples S5, S8 and S9 were characterized by the largest amount of paraffin wax inside them. More than $40 \%$ of this subset of samples (S1 to S9) had $>20 \%$ of their volumes filled with paraffin wax, which can affect the representativeness of sample volume or bulk density evaluation (Grossman and Reinsch, 2002; Russell and Balcerek, 1944). The presence of cracks and macropores can contribute to the penetration of paraffin wax (Casanova et al., 2016; Gonçalves et al., 2013; Sander and Gerke, 2007; Page-Dumroese et al., 1999; Schafer and Singer, 1976).

To further consider the influence of the soil sample structure in the penetration of paraffin wax, 3D pore size and shape distribution measurements were undertaken (Fig. 4). Values of normalized average P, PV and NP, as a function of the shape and size of number of pores was within the range of 0.0001 to $0.01 \mathrm{~mm}^{3}$, which varied from $\approx 93 \%$ (S6) to $\approx 97 \%$ (S1) (Fig. 4b). Similar results were also observed in similar studies for Brazilian tropical soils (Ferreira et al., 2018; Passoni et al., 2015). shape were similar among samples (S1 to S9) (Figs. 4c-f). The largest contribution to PV was from the unclassified pores, from $\approx 54 \%(S 1)$ to $\approx 66 \%$ (S4), while the smallest was for equant (S4: $\approx 3 \%$; S1: $\approx 6 \%$ ) and oblate (S4: $\approx 5 \%$; S7: $\approx 6 \%$ ) shaped pores (Fig. 4c). The same tendency was observed for NP, which demonstrates the relation between PV and NP (Fig. 4d). In summary, the unclassified pores contributed to $\approx 61 \%$ of PV and $\approx 77 \%$ of NP followed by the triaxial shaped pores (PV: $\approx 21 \%$ and NP: $\approx 10 \%$ ) (Figs. 4c,d).

When the unclassified pores were not considered in the analysis (Figs. 4e,f), the largest contribution to PV was for the triaxial shaped pores from $\approx 49 \%(\mathrm{~S} 1)$ to $\approx 58 \%$ (S3), 
341 while the smallest was for equant (S6: $\approx 8 \%$; S1: $\approx 13 \%$ ) (Fig. $4 \mathrm{e})$. The objective of

342 excluding unclassified pores was to ensure the evaluation was only for those pores 343 classified by the shape index where paraffin wax ingress had taken place. The same 344 tendency was observed for NP, which demonstrates the relation between PV and NP 345 (Fig. 4f).

It is important to note that triaxial (laminar), oblate (disk) and prolate (channel) pores have elongated shapes while equant are spheroidal (Bullock et al., 1985). Cracks and thin fissures are usually associated with elongated pores, whereas fauna activity and trapped air is associated with the spherical ones (Pagliai, 1984). As described early, a large proportion of the pore space $(\approx 77 \%$ among samples) in this study were not classified in terms of shape due to the extent of their complexity (Tseng et al., 2018; Pires et al, 2017). Nevertheless, we noted that the pore size and shape distribution results cannot completely explain the differences observed in the amount of paraffin wax in the samples (Table 3). Therefore, a further analysis of the pore size and shape distribution was performed considering only the regions of the sample pore space filled with paraffin wax.

\subsection{Pore size and shape distribution (regions filled with paraffin)}

In terms of pore size distribution, the largest contribution to $P$ was found for the single, largest pore $\left(>10 \mathrm{~mm}^{3}\right)$, similar to the results of the whole soil porous system (Fig. 4a). Exceptions were S3 and S4 (results not showed in the paper), which had contributions of $\approx 27 \%$ and $\approx 20 \%$ for these pore sizes (Fig. $4 a$ ). The samples with the

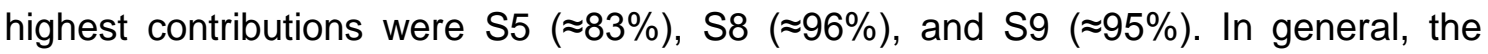
samples with the largest contribution of large pores to $\mathrm{P}$ were also those with the highest amount of paraffin wax inside them $(r=0.68, p<0.05)$ (Tables 1 and 3). Sample S7 was an exception (results not showed in the paper), as it was characterized by the highest NP $(\approx 93 \%)$ in the region of sizes of 0.1 to $1.0 \mathrm{~mm}^{3}$ (Fig. $\left.4 \mathrm{~b}\right)$. As observed for the contribution of large pores to $\mathrm{P}$, in general, samples with the highest NP for pore sizes 
$>1 \mathrm{~mm}^{3}$ (S5: $\approx 19 \%$; S8: $\approx 24 \%$; S9: $\approx 22 \%$ ) were also those with the largest amount of paraffin wax inside them (Figs. 4a,b). Large pores are very important and their key function in the soil porous system is to facilitate the movement of air and drainage of solutes (Lal and Shukla, 2004). Therefore, less energy is required to fill these pores with paraffin wax (Kutílek and Nielsen, 1994).

For pore shape, the largest and the smallest contribution to PV and NP was again observed for pores unclassified in terms of shape (PV: $\approx 86 \%$ and NP: $\approx 74 \%$ ) (Figs. 4c,d). This was expected because the largest amount of paraffin wax ingressed inside the soil samples was found in the largest pores, which are characterized by their complexity (Fig. 2).

When pores not classified in terms of their shape were excluded, the largest and the smallest contribution to PV was observed for triaxial (S3: $\approx 55 \%$; S4: $\approx 93 \%$ ) and equant (S1: $\approx 0 \% ; \mathrm{S6}: \approx 3 \%$ ) shaped pores (Fig. $4 \mathrm{e}$ ). The same tendency was verified for NP (S3: $\approx 65 \%$; S4: $\approx 87 \%$ for triaxial and S1: $\approx 0 \%$; S8: $\approx 4 \%$ for equant) (Fig. $4 f$ ). However, as observed in Fig. 4c, the largest proportion of pore volumes ( $\approx 86 \%$ ) filled with paraffin wax was verified for the unclassified pores in terms of shape. A strong positive correlation $(r=0.72, p<0.05)$ was measured between the volume of paraffin wax inside the samples and the percentage of unclassified pores. This means that the paraffin wax tends to penetrate in the largest pores, which are also more complex. Similar to the results for the whole soil porous system, there was a clear relationship between PV and NP for the pores classified in terms of shape. This suggests pores of triaxial shape offer less resistance to be filled with paraffin wax than the other shapes. Normally, this pore shape is associated with fissures in the samples. In general, the samples with the largest proportion of paraffin wax $(\mathrm{S} 5, \mathrm{~S} 6, \mathrm{~S} 8)$ were also characterized by the most abundant proportion of oblate and triaxial pore shapes (unclassified pores not included) in terms of PV ( $r=0.56, p=0.15$, S9 not included) (Fig. 4e). An exception was observed for S9, which presented $\approx 31 \%$ of PV due to prolate shaped pores (results not showed in the 
paper). For NP (Fig. 4f), S4 followed by S9, S8 and S5 presented the largest proportions of the contribution of triaxial shaped pores to NP (S4: $\approx 87 \%$; S9: $\approx 77 \%$; S8: $\approx 72 \%$; S5: $\approx 71 \%$ ). However, there was no a clear relation between the amount of paraffin wax inside the samples and NP $(r=-0.04)$.

\subsection{Soil bulk density measurement}

To evaluate the effect of the paraffin wax into the soil samples in BD measurements we selected two groups of samples. The first (group 1) were clods collected to evaluate the influence of the paraffin wax ingress when the paraffin-coated method is used. The results show that the entrance of paraffin wax into the samples of group 1 presented significant $(p \leq 0.05)$ changes in BD (Table 5). An increase of around $0.11 \mathrm{~g} \mathrm{~cm}^{-3}$ was measured in BD after the entrance of paraffin wax. Different from samples from group 3, the paraffin wax ingress into the soil samples from groups 1 and 2 were verified based on the visual examination and not by image analysis.

In order to verify that the BD increase was not influenced by the soil spatial variability, we also carried out measurements of BD by the core method (samples of group 2). These samples were later carefully removed from the stainless cylinders for coating with paraffin wax. A reduction of around $25 \mathrm{~cm}^{3}$ in the volume of the samples analyzed was verified after their removal from the cylinders, which significantly increased $(p \leq 0.05)$ their BD (Table 5). However, when the same set of samples (group 2) was analyzed by the core method before coating, no significant $(p \leq 0.05)$ differences were observed in the average $\mathrm{BD}\left(1.04 \mathrm{~g} \mathrm{~cm}^{-3}\right.$ - samples with no paraffin wax ingress and $1.03 \mathrm{~g} \mathrm{~cm}^{-3}$ - samples with paraffin wax ingress after coating), which means that the differences were caused by the ingress of paraffin wax inside the soil samples (Figs. 1d and 2) and not by their spatial variability. According to van Remortel and Shields (1993), the ingress of paraffin wax into soil clods can reduce their measured volume, and, consequently it results in a higher BD as observed in our results (Solgi et al., 2018). 

because clod samples normally overestimates $B D$ from 0.07 to $0.22 \mathrm{~g} \mathrm{~cm}^{-3}$ in relation to core samples, as has been previously shown in the literature (Solgi et al., 2018; Casanova et al., 2016; Gonçalves et al., 2013; Timm et al., 2005; van Remortel and Shields, 1993; Blake and Hartge, 1986). This is based on the tendency of clods collected to exclude pores between structural units. However, our results show that this overestimation could be greater if paraffin wax penetrates into the samples during coating as observed for samples of group 2 (Table 5). This result certainly depends on the characteristics of the soil studied, however, similar findings were observed by Auler et al. (2017) working with another Brazilian Oxisol.

An analysis of the image cross-sections revealed the samples with the largest amount of ingressed paraffin wax had a considerable number of large pores close to their borders (Fig. 2). This analysis was mainly based on visual analysis of the X-ray CT images. This result means that samples with these characteristics are more susceptible to paraffin wax penetration. To avoid this problem one suggestion might be to check the quality of the aggregates before coating. Aggregates with a strong grade structure (wellformed and durable) certainly have the smaller probability of paraffin wax be absorbed deep into them than poorly formed and nondurable ones (Hirmas and Furquim, 2006; Hillel, 2004). However, another possibility would be to increase the number of replicates to minimize the influence of this problem. For instance, in this study we used a great number of samples $(n=36)$ and $75 \%$ of the coated samples did not present significant ingress of paraffin wax deep into them.

\section{Conclusions}

The use of X-ray CT allowed us to verify the influence of different soil morphological parameters (shape of pores, pore size distribution, porosity, number of pores, connectivity, tortuosity and degree of anisotropy) in the amount of paraffin wax ingress inside soil samples. We found positive correlations between the amount of 
paraffin wax into the samples and their pore volume, tortuosity and degree of anisotropy

449

450

451

452

453

454

455

456

457

458

459

460

461

462

463

464

465

466

467

468

469

470

471

472

473

for the region of interest analyzed. Contrary to our expectation, no relation was found between the volume of paraffin wax inside the samples and the porous system connectivity, which can be associated with the volume studied by image analysis. Our results showed that the samples with the largest contribution of large pores to porosity were also those with the highest amount of paraffin wax inside them. The analysis of the pores classified in terms of shape suggested that those with moderately to very flat and moderately to very elongate shapes (triaxial shaped pores) had the greatest influence in the ingress of paraffin wax into the samples. However, the largest pores, which were not classified in terms of shape, had the great influence in the penetration of paraffin wax inside the samples. For the soil samples analyzed, the soil bulk density was increased, when the paraffin wax penetration into the samples was observed. This result is associated to the lowering of the actual volume of the soil due to the ingress of paraffin wax in the clod method used in this work. Thus, we have shown the paraffin-coated method is prone to problems in measurements of soil bulk density due to the paraffin wax penetration, though it does not apply to all soils and with careful selection of samples and increased replication the impact could be minimized.

\section{Acknowledgments}

LFP would like to acknowledge the financial support provided by the Brazilian National Council for Scientific and Technological Development (CNPq) and the Coordination for the Improvement of Higher Education Personnel (Capes) through the Grants 303726/2015-6 (Productivity in Research) and 88881.119578/2016-01 (Visiting Scholar). We would like to thanks Dr. Waldir L. Roque from the Federal University of Paraíba, Brazil, for the development of the software for the analysis of connectivity and tortuosity. We also would like to express our gratitude to the comments and suggestions of the two reviewers, which contributed a lot to improve the quality of the paper. 


\section{References}

475

476

477

478

479

480

481

482

483

484

485

486

487

488

489

490

491

492

493

494

495

496

497

498

Auler, A.C., Pires, L.F., Brinatti, A.M., Saab, S.C., 2017. Soil aggregates bulk density: The use of Jolly balance in experimental physics classes for soil science education. Rev. Bras. Ens. Física, 39, e1506-1-e1506-8.

Blake, G.R., Hartge, K.H., 1986. Bulk density, in: Klute, A. (Ed.), Methods of Soil Analysis, Part 1: Physical and Mineralogical Methods, Soil Science Society of America, Madison, WI, pp. 363-382.

Borges, J.A.R., Pires, L.F., Cássaro, F.A.M., Roque, W.L., Heck, R.J., Rosa, J.A., Wolf, F., 2018. X-ray microtomography analysis of representative elementary volume (REV) of soil morphological and geometrical properties. Soil Tillage Res. 182, 112-122.

Brewer, R., 1964. Fabric and mineral analysis of soils. New York: Wiley.

Bullock, N., Fedoroff, A., Jongerius, A., Stoops, G., Tursina, T., 1985. Handbook for Soil Thin Section Description, 1st ed. Waine Research, England.

Carducci, C.E., Zinn, Y.L., Rossoni, D.F., Heck, R.J., Oliveira, G.C., 2017. Visual analysis and X-ray computed tomography for assessing the spatial variability of soil structure in a cultivated Oxisol. Soil Tillage Res. 173, 15-23.

Casanova, M., Tapia, E., Seguel, O., Salazar, O., 2016. Direct measurement and prediction of bulk density on alluvial soils of central Chile. Chilean J. Agric. Res. 76, $105-113$.

Chappard, D., Legrand, E., Pascaretti, C., Baslé, M.F., Audran, M., 1999. Comparison of eight histomorphometric methods for measuring trabecular bone architecture by image analysis on histological sections. Microsc. Res. Tech. 45, 303-312.

Cnudde, V., Boone, M.N., 2013. High-resolution X-ray computed tomography in geosciences: A review of the current technology and applications. Earth-Sci. Rev. 123, $1-17$. 
499 Crestana, S., Mascarenhas, S., Pozzi-Mucelli, R.S., 1985. Static And Dynamic 3 500 Dimensional Studies Of Water In Soil Using Computed Tomographic Scanning. Soil 501 Sci. 140, 326-332.

502 Doube, M., Kłosowski, M.M., Arganda-Carreras, I., Cordelières, F.P., Dougherty, R.P., 503 Jackson, J.S., Schmid, B., Hutchinson, J.R., Shefelbine, S.J., 2010. BoneJ: Free and 504 extensible bone image analysis in ImageJ. Bone 47, 1076-1079.

505 Ferreira, T.R., Pires, L.F., Wildenschild, D., Heck, R.J., Antonino, A.C.D., 2018. X-ray 506 microtomography analysis of lime application effects on soil porous system. 507 Geoderma 324, 119-130.

508 Gantzer, C.J., Anderson, S.H., 2002. Computed tomographic measurement of 509 macroporosity in chisel-disk and no-tillage seedbeds. Soil Till. Res. 64, 101-111.

510 Gonçalves, F.C., Marasca, I., de Souza, S.F.G., Tavares, L.A.F., Silva, P.R.A., 2013. 511 Métodos de determinação da densidade do solo em diferentes sistemas de manejo. $512 \quad$ Energ. Agric. 28, 165-169.

513 Grayling, K.M., Young, S.D., Roberts, C.J., de Heer, M.I., Shirley, I.M., Sturrock, C.J., 514 Mooney, S.J., 2018. The application of X-ray micro Computed Tomography imaging 515 for tracing particle movement in soil. Geoderma 321, 8-14.

516 Grossman, R.B., Reinsch, T.G., 2002. Water retention and storage, in: Dane, J.H., Topp, 517 G.C. (Eds.), Methods of Soil Analysis. Part 4: Physical Methods. Soil Science Society 518 of America, Madison, WI, pp. 201-228.

519 Håkansson, I., Lipiec, J., 2000. A review of the usefulness of relative bulk density values 520 in studies of soil structure and compaction. Soil Till. Res. 53, 71-85.

521 Hammer, Ø., Harper, D.A.T., Ryan, P.D., 2001. PAST: Paleontological statistics software 522 package for education and data analysis. Palaeont. Elect. 4, 1-9.

523 Hillel, D., 2004. Introduction to Environmental Soil Physics. Elsevier Academic Press, 524 Burlington, Massachusetts, USA. 
525 Hirmas, D.R., Furquim, S.A.C., 2006. Simple modification of the clod method for 526 determining bulk density of very gravelly soils. Commun. Soil Sci. Plan. 37, 899-906.

527 Holden, N.M., 1994. A rapid method for the visualisation of soil macropores. Plant Soil $528 \quad 166,291-294$.

529 Hounsfield, G.N., 1973. Computerized transverse axial scanning (tomography): I. 530 Description of system. Br. J. Radiol. 46, 1016-1022.

531 Jefferies, D.A., Heck, R.J., Thevathasan, N. V., Gordon, A.M., 2014. Characterizing soil 532 surface structure in a temperate tree-based intercropping system using X-ray 533 computed tomography. Agrofor. Syst. 88, 645-656.

534 Jury, W.A., Horton, R.C.N., 2004. Soil physics, 6th ed. John Wiley, Hoboken, NJ, USA.

535 Katuwal, S., Norgaard, T., Moldrup, P., Lamandé, M., Wildenschild, D., de Jonge, L.W., 536 2015. Linking air and water transport in intact soils to macropore characteristics 537 inferred from X-ray computed tomography. Geoderma 237/238, 9-20.

538 Kutílek, M., Nielsen, D.R., 1994. Soil Hydrology. Catena Verlag, Germany.

539 Lal, R., Shukla, M.K., 2004. Principles of Soil Physics. CRC Press, New York, NY, USA.

540 Luo, L.F., Lin, H., Li, S.C., 2010. Quantification of 3-D soil macropore networks in 541 different soil types and land uses using computed tomography. J. Hydrol. 393, 53-64.

542 Mooney, S.J., Pridmore, T.P., Helliwell, J., Bennett, M.J., 2012. Developing X-ray 543 Computed Tomography to non-invasively image 3-D root systems architecture in soil. $544 \quad$ Plant Soil 352, 1-22.

545 Odgaard, A., Gundersen, H.J.G., 1993. Quantification of connectivity in cancellous bone, 546 with special emphasis on 3-D reconstructions. Bone 14, 173-182.

547 Or, D., Wraith, J.M., 2002. Soil water content and water potential relationships, in: 548 Warrick, A.W. (Ed.), Soil Physics Companion, CRC Press, Boca Raton, pp. 49-84. 
549 Otsu, N., 1979. A threshold selection method from gray-level histograms. IEEE 550 Transactions on Systems, Man and Cybernetics I. SMC-9, 62-6.

551 Page-Dumroese, D.S., Jurgensen, M.F., Brown, R.E., Mroz, G.D., 1999. Comparison of 552 methods for determining bulk densities of rocky forest soils. Soil Sci. Soc. Am. J. 63, $553 \quad 379-383$.

554 Pagenkemper, S.K., Puschmann, D.U., Peth, S., Horn, R., 2014. Investigation of time 555 dependent development of soil structure and formation of macropore networks as 556 affected by various precrop species. Intern. Soil Water Cons. Res. 2, 51-66.

557 Pagliai, M., La Marca, M., Lucamante, G., Genovese, L., 1984. Effects of zero and 558 conventional tillage on the length and irregularity of elongated pores in a clay loam soil under viticulture. Soil Tillage Res. 4, 433-444.

Passoni, S., Pires, L.F., Heck, R., Rosa, J.A., 2015. Three dimensional characterization of soil macroporosity by X-ray microtomography. Rev. Bras. Ciência do Solo 39, 448562 457.

Pires, L.F., Borges, J.A.R., Bacchi, O.O.S., Reichardt, K., 2010. Twenty-five years of computed tomography in soil physics: A literature review of the Brazilian contribution. Soil Tillage Res. 110, 197-210.

Pires, L.F., Rosa, J.A., Timm, L.C., 2011. Comparação de métodos de medida da densidade do solo. Acta Sci. Agron. 33, 161-170.

Pires, L.F., Borges, J.A.R., Rosa, J.A., Cooper, M., Heck, R., Passoni, S., Roque, W.L., 2017. Soil structure changes induced by tillage systems. Soil Tillage Res. 165, 66-79.

570 Pires, L.F., 2018. Soil analysis using nuclear techniques: A literature review of the 571 gamma ray attenuation method. Soil Tillage Res. 184, 216-234.

572 Rasband, W., 2007. ImageJ.1997-2007. U.S.National Institutes of Health, Bethesda, 573 MD, USA. 
574 Rezanezhad, F., Quinton, W.L., Price, J.S., Elrick, D., Elliot, T.R., Heck, R.J., 2009.

575 Examining the effect of pore size distribution and shape on flow through unsaturated

576 peat using computed tomography. Hydrol. Earth Syst. Sci. 13, 1993-2002.

577 Roque, W.L., Souza, A.C.A. de, Barbieri, D.X., 2009. The Euler-Poincaré characteristic

578 applied to identify low bone density from vertebral tomographic images. Rev. Bras.

579 Reumatol. 49, 140-52.

580 Roque, W.L., Arcaro, K., Alberich-Bayarri, A., 2012a. Tortuosity and elasticity study of 581 distal radius trabecular bone, in: Rocha, Á., Calvo-Manzano, J.A., Reis, L.P., Cota, 582 M.P. (Eds.), Sistemas Y Tecnologías de Información: Actas de La 7a Conferencia 583 Ibérica de Sistemas Y Tecnologías de Información. APPACDM - Associação 584 Portuguesa de Pais e Amigos do Cidadão Deficiente Mental, Madrid, pp. 1-4.

585 Roque, W.L., Arcaro, K., Lanfredi, R.B., 2012b. Trabecular network tortuosity and 586 connectivity of distal radius from microtomographic images. Brazilian J. Biomed. Eng. $587 \quad 28,116-123$.

588 Rossi, A.M., Hirmas, D.R., Graham, R.C., Sternberg, P.D., 2008. Bulk density 589 determination by automated three-dimensional laser scanning. Soil Sci. Soc. Am. J. $590 \quad 72,1591-1593$.

591 Russell, E.W., Balcerek, W., 1944. The determination of the volume and air space of soil 592 clods. J. Agric. Sci. 34, 123-132.

593 San José Martínez, F., Caniego, F.J., García-Gutiérrez, C., 2017. Lacunarity of soil 594 macropore space arrangement of CT images: Effect of soil management and depth. 595 Geoderma 287, 80-89.

596 Sander, T., Gerke, H.H., 2007. Noncontact shrinkage curve determination for soil clods 597 and aggregates by three-dimensional optical scanning. Soil Sci. Soc. Am. J. 71, 14485981454 
599 Schafer, W.M., Singer, M.J., 1976. Reinvestigation of effect of saran coatings on 600 extensibility of swelling soil clods. Soil Sci. 122, 360-364.

601 Schmitt, M., Halisch, M., Müller, C., Fernandes, C.P., 2016. Classification and 602 quantification of pore shapes in sandstone reservoir rocks with 3-D X-ray micro603 computed tomography. Solid Earth 7, 285-300.

604 Shipp, R.F., Matelski, R.P., 1965. Bulk-density and coarse-fragment determinations on 605 some Pennsylvania soils. Soil Sci. 99, 392-397.

606 Solgi, A., Naghdi, R., Labelle, E.R., Tsioras, P.A., Salehi, A., 2018. Comparison of 607 sampling methods used to evaluate forest soil bulk density. Croat. J. Eng. 39, 107$608 \quad 114$.

609 Staff, S.S., 2013. Simplified guide to soil taxonomy. USDA-Natural Resources 610 Conservation Service, National Soil Survey Center, Lincoln, USA.

611 Stewart, R.D., Abou Najm, M.R., Rupp, D.E., Selker, J.S., 2012. An image-based method 612 for determining bulk density and the soil shrinkage curve. Soil Sci. Soc. Am. J. 76, $613 \quad 1217-1221$.

614 Timm, L.C., Pires, L.F., Reichardt, K., Roveratti, R., Oliveira, J.C.M., Bacchi, O.O.S., 615 2005. Soil bulk density evaluation by conventional and nuclear methods. Aust. J. Soil 616 Res. 43, 97-103.

617 Toriwaki, J., Yonekura, T., 2002. Euler number and connectivity indexes of a three 618 dimensional digital picture. Forma 17, 183-209.

619 Tseng, C.L, Alves, M.C., Crestana, S., 2018. Quantifying physical and structural soil 620 properties using X-ray microtomography. Geoderma 318, 78-87.

621 Turner, W.R., Brown, D.S., Harrison, D.V., 1955. Properties of paraffin waxes: 622 composition by mass spectrometer analysis. Ind. Eng. Chem. 46, 1219-1226. 
623 van Remortel, R.D., Shields, D.A., 1993. Comparison of clod and core methods for 624 determination of soil bulk density. Commun Soil Sci Plant Anal. 24, 2517-2528.

625 Vaz, C.M.P., de Maria, I.C., Lasso, P.O., Tuller, M., 2011. Evaluation of an advanced 626 benchtop micro-computed tomography system for quantifying porosities and pore-size 627 distributions of two Brazilian Oxisols. Soil Sci. Soc. Am. J. 75, 832-841.

628 Vogel, H.J., Kretzshmar, A., 1996. Topological characterization of pore space in soil 629 sample preparation and digital image-processing. Geoderma 73, 23-38.

630 Zingg, T., 1935. Beitrag zur Schotteranalyse. Schweiz. Mineral. Petrogr. Mitt., 15, 39631140. 


\section{Figure Captions}

Figure 1. $(a, b)$ Pictures of the sample coating with paraffin wax; (c) Picture of soil samples submitted to coating; (d) Paraffin wax inside one of the soil samples.

Figure 2. 3D images of one of the samples (S8) impregnated with paraffin wax. The three images on top represent the volume of pores, paraffin and solids, respectively. The graph presents the grey level histogram for one of the cross-sections analyzed. Arrows 1 to 4 indicate large and connected macropores close to the border of the sample.

Figure 3. Micromorphological characteristics of the soil samples. (a) Porosity (P); (b) Pore volume (PV); (c) Number of pores (NP); (d) Volumetric Euler-Poincare characteristic (EPCV); (e) Tortuosity (T); (f) Degree of anisotropy (DA).

Figure 4. (a) Normalized distributions of the mean porosity $\left(P_{N}\right)$ in terms of different pore sizes; (b) Normalized distributions of the mean number of pores $\left(N P_{N}\right)$ in terms of different pore sizes; (c) Normalized distributions of mean pore volume $\left(P V_{N}\right)$ in terms of the shape of pores; (d) Normalized distributions of the mean number of pores $\left(N P_{N}\right)$ in terms of the shape of pores; (e) Normalized distributions of mean pore volume $\left(P V_{N}\right)$ in terms of the shape of pores not considering the non-classified pores; (f) Normalized distributions of the mean number of pores (NPN) in terms of the shape of pores not considering the non-classified pores. The results are presented for the whole soil porous system ( $\square$ ) and pores filled with paraffin wax (๑). Bars indicate standard deviation of the mean. EQ: Equant; PR: Prolate; OB: Oblate; TR: Triaxial. 


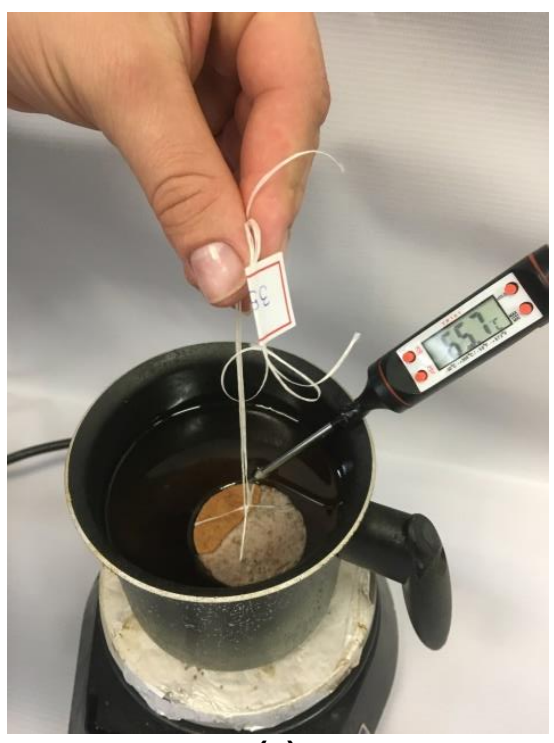

(a)

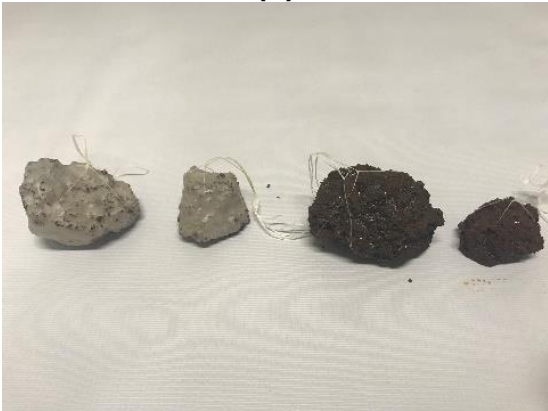

(c)

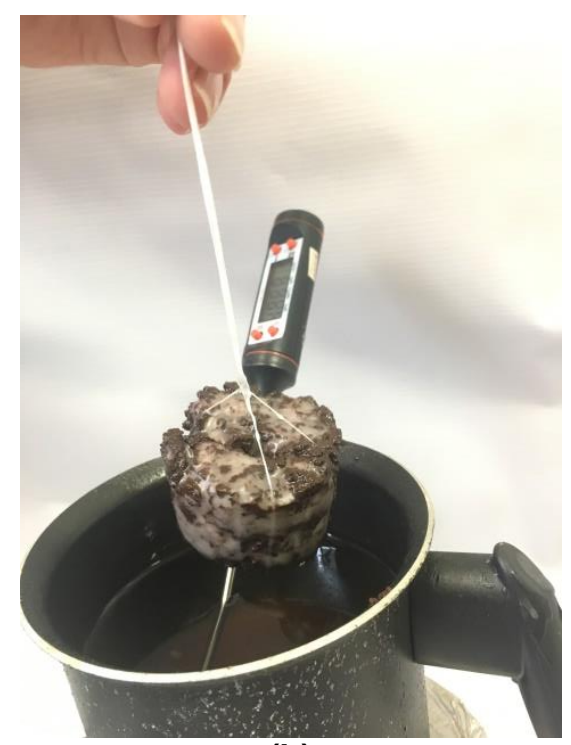

(b)

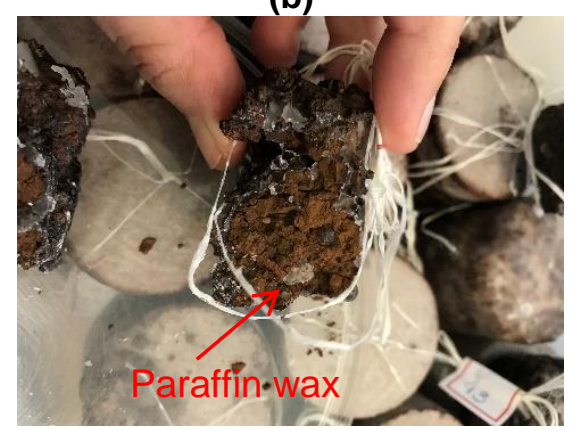

(d)

Figure 1. $(a, b)$ Pictures of the sample coating with paraffin wax; (c) Picture of soil samples submitted to coating; (d) Paraffin wax inside one of the soil samples. 


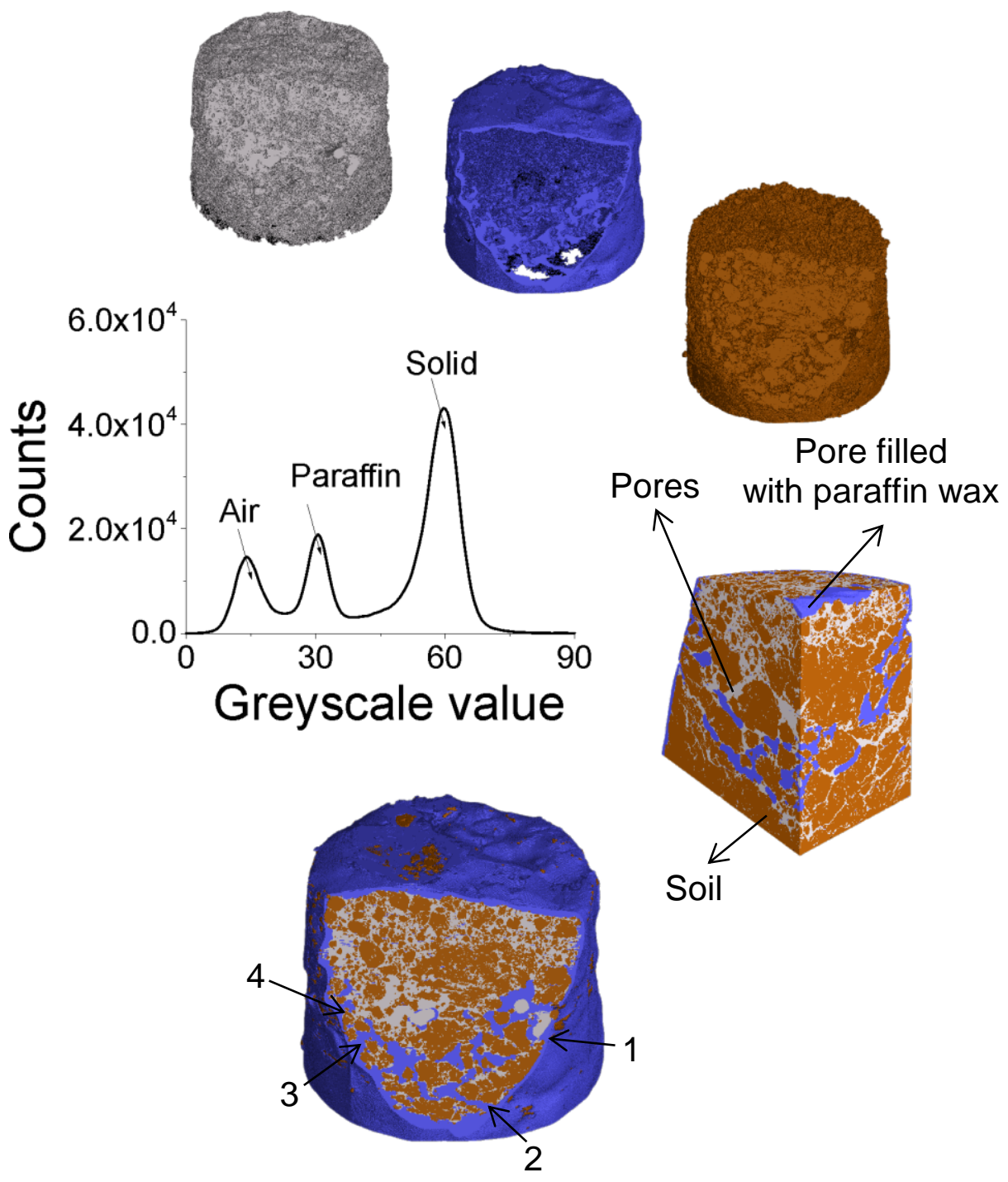

Figure 2. 3D images of one of the samples (S8) impregnated with paraffin wax. The three images on top represent the volume of pores, paraffin, and solids, respectively. The graph presents the grey level histogram for one of the cross-sections analyzed. Arrows 1 to 4 indicate large and connected macropores close to the border of the sample. 


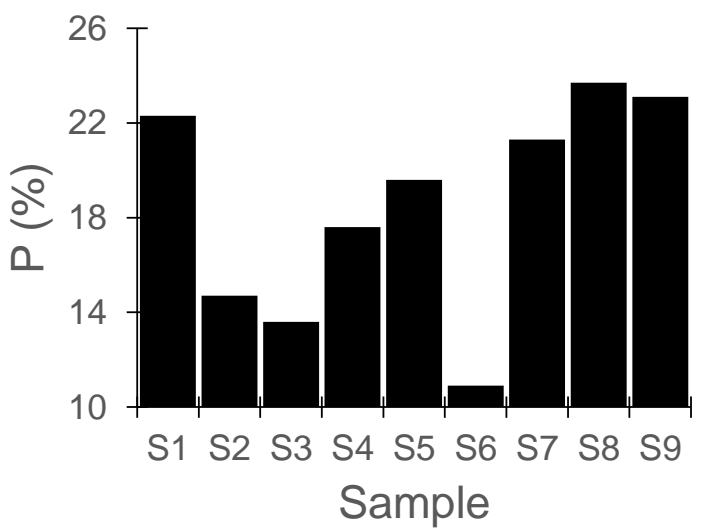

(a)

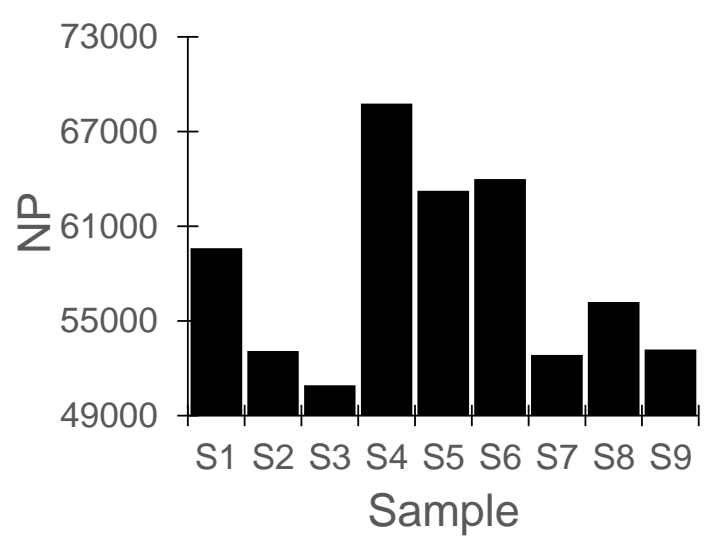

(c)

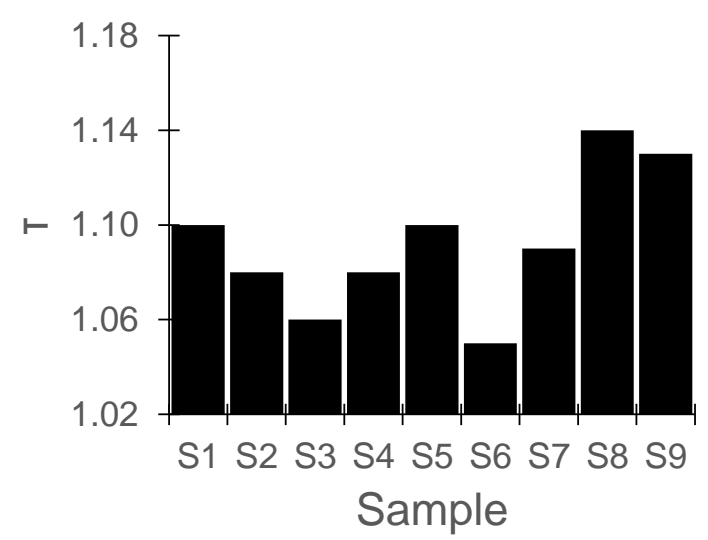

(e)

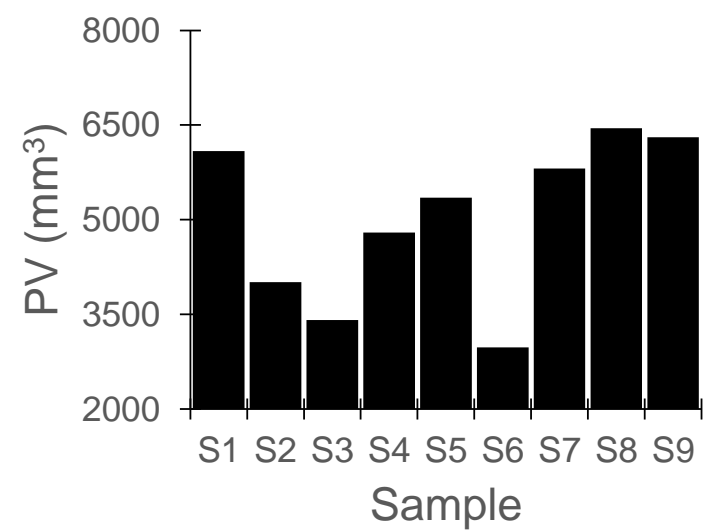

(b)

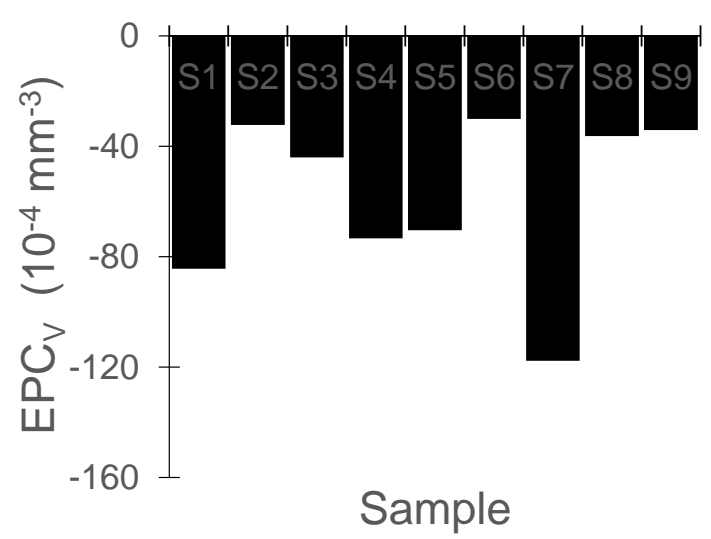

(d)

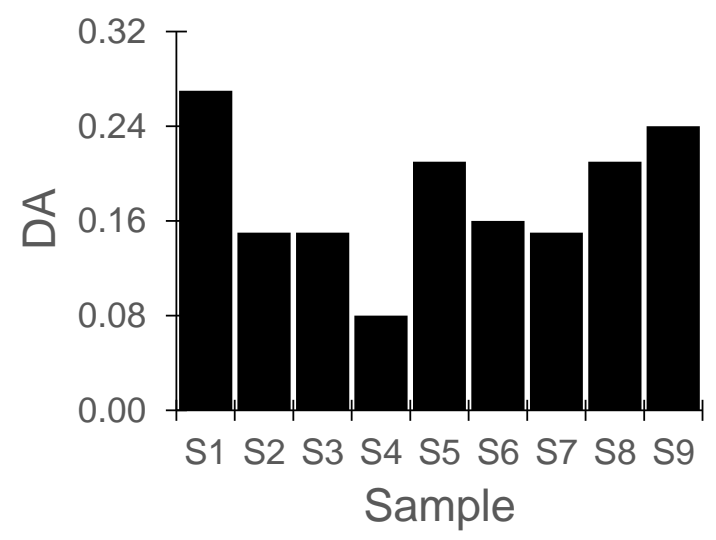

(f)

Figure 3. Micromorphological characteristics of the soil samples. (a) Porosity (P); (b) Pore volume (PV); (c) Number of pores (NP); (d) Volumetric Euler-Poincare characteristic $\left(\mathrm{EPC}_{\mathrm{V}}\right)$; (e) Tortuosity (T); (f) Degree of anisotropy (DA). 


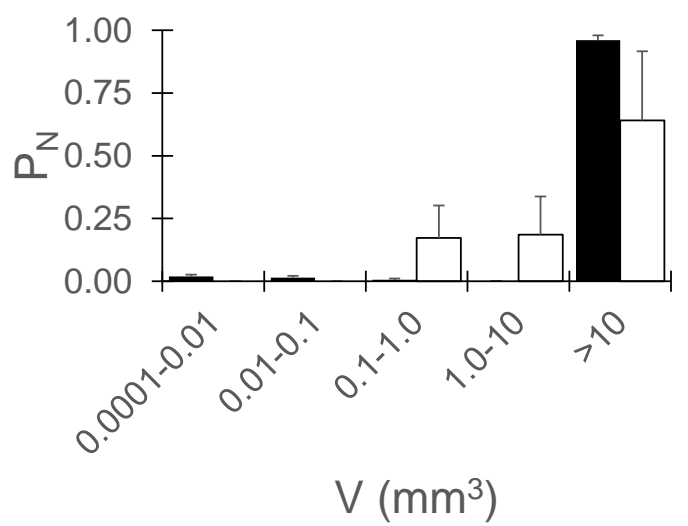

(a)

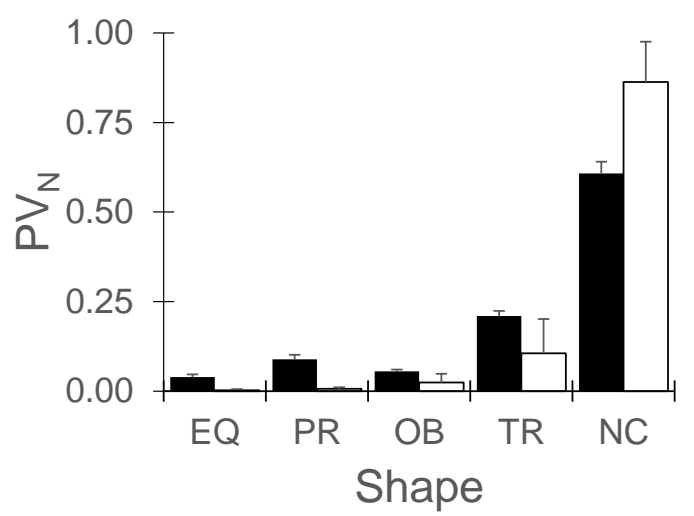

(c)

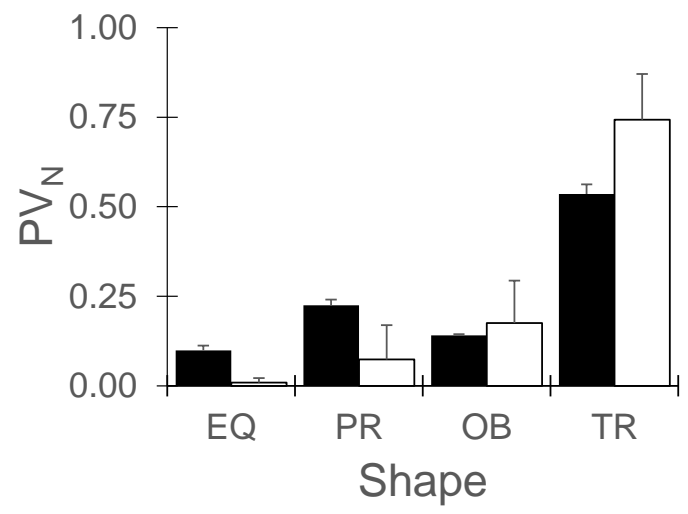

(e)

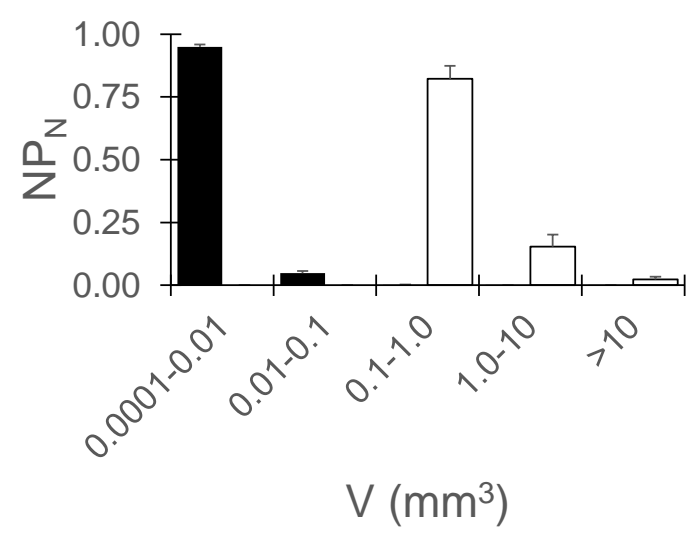

(b)

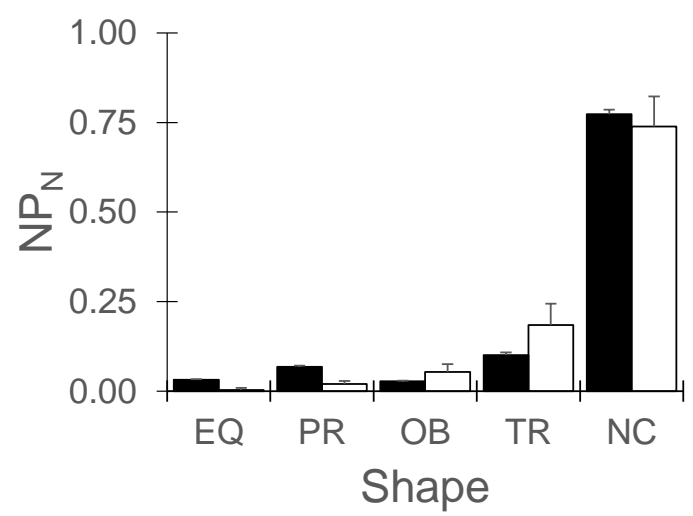

(d)

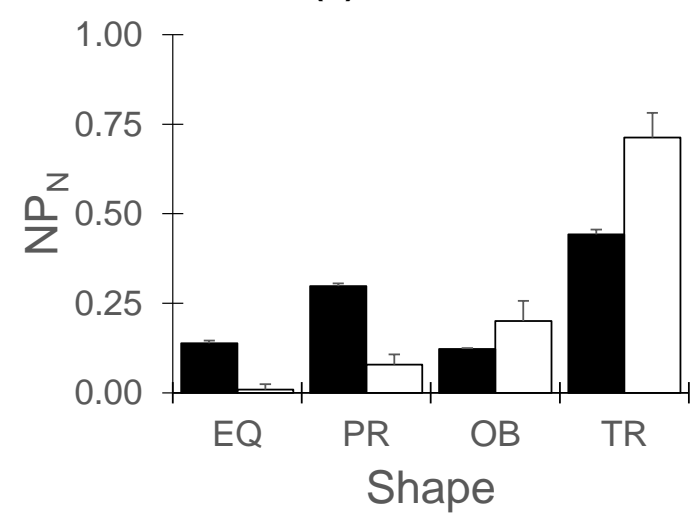

(f)

Figure 4. (a) Normalized distributions of the mean porosity $\left(\mathrm{P}_{\mathrm{N}}\right)$ in terms of different pore sizes; (b) Normalized distributions of the mean number of pores $\left(N P_{N}\right)$ in terms of different pore sizes; (c) Normalized distributions of mean pore volume $\left(\mathrm{PV}_{\mathrm{N}}\right)$ in terms of the shape of pores; (d) Normalized distributions of the mean number of pores $\left(N P_{N}\right)$ in terms of the shape of pores; (e) Normalized distributions of mean pore volume $\left(P V_{N}\right)$ in terms of the shape of pores not considering the non-classified pores; (f) Normalized distributions of the mean number of pores (NPN) in terms of the shape of pores not considering the non-classified pores. The results are presented for the whole soil porous system ( $\square$ ) and pores filled with paraffin wax ( $\square$ ). Bars indicate standard deviation of the mean. EQ: Equant; PR: Prolate; OB: Oblate; TR: Triaxial. 
Table 1. Pearson correlation coefficients among soil morphological parameters studied

\begin{tabular}{|c|c|c|c|c|c|c|c|c|c|c|}
\hline Property & no. & 1 & 2 & 3 & 4 & 5 & 6 & 7 & 8 & 9 \\
\hline $\mathrm{PV}\left(\mathrm{mm}^{3}\right)$ & 1 & 1.00 & & & & & & & & \\
\hline $\mathbf{P}(\%)$ & 2 & $0.99^{\star *}$ & 1.00 & & & & & & & \\
\hline NP & 3 & -0.12 & -0.16 & 1.00 & & & & & & \\
\hline $\mathrm{PaV}\left(\mathrm{mm}^{3}\right)$ & 4 & $0.68^{\star}$ & $0.68^{\star}$ & -0.04 & 1.00 & & & & & \\
\hline$E P C_{V}$ & 5 & -0.38 & -0.38 & -0.12 & 0.31 & 1.00 & & & & \\
\hline Tavg & 6 & $0.91^{\star *}$ & $0.91^{* *}$ & -0.20 & $0.87^{\star \star}$ & 0.09 & 1.00 & & & \\
\hline DA & 7 & 0.58 & 0.58 & -0.25 & $0.67^{\star}$ & 0.13 & 0.60 & 1.00 & & \\
\hline $\mathrm{EN}_{\mathrm{B}}$ & 8 & -0.40 & -0.40 & -0.41 & 0.18 & 0.45 & -0.04 & -0.07 & 1.00 & \\
\hline$E N_{>0.2}$ & 9 & 0.39 & -0.39 & -0.41 & 0.19 & 0.45 & -0.04 & -0.07 & $0.99^{\star \star}$ & 1.00 \\
\hline
\end{tabular}

$\mathrm{PV}\left(\mathrm{mm}^{3}\right)$ : pore volume; $\mathrm{P}(\%)$ : porosity; NP: number of pores; $\mathrm{PaV}\left(\mathrm{mm}^{3}\right)$ : paraffin wax volume; $\mathrm{EPC}_{\mathrm{V}}$ : Volumetric EulerPoincare Characteristic; Tavg: average tortuosity; DA: degree of anisotropy; Th $(\mathrm{mm})$ : macropore thickness; EN $\mathrm{B}_{\mathrm{B}}$ : Euler number (largest pore); $\mathrm{EN}_{>0.2}$ : Euler number for pores larger than $0.2 \mathrm{~mm}^{3} ;{ }^{*},{ }^{* *}$ significantly different at $\mathrm{p}<0.05$ and $\mathrm{p}<0.01$

Table 2. Morphological characteristics of the soil porous system (whole sample) for pores larger than $0.2 \mathrm{~mm}^{3}$

\begin{tabular}{cccccccccc}
\hline Sample & S1 & S2 & S3 & S4 & S5 & S6 & S7 & S8 & S9 \\
\hline PV $_{>0.2}\left(\mathbf{m m}^{3}\right)$ & 5953 & 3841 & 3252 & 4621 & 5193 & 2762 & 5673 & 6291 & 6148 \\
$\mathbf{P}_{>0.2}(\%)$ & 21.8 & 14.1 & 11.9 & 17.0 & 19.0 & 10.1 & 20.8 & 23.1 & 22.5 \\
$\mathbf{N P}_{>0.2}$ & 9 & 50 & 41 & 33 & 21 & 64 & 15 & 33 & 23 \\
$\mathbf{E N}_{>0.2^{*}}$ & -25 & -9 & -12 & -21 & -20 & -9 & -21 & -11 & -10 \\
\hline
\end{tabular}

${ }^{*}$ All the values of $\mathrm{EN}_{>0.2}$ presented should be multiplied for $\times 10^{4}$

Table 3. Volume of pores occupied by paraffin wax in the region of interest studied

\begin{tabular}{cccccccccc}
\hline Sample & S1 & S2 & S3 & S4 & S5 & S6 & S7 & S8 & S9 \\
\hline $\mathbf{P}_{\mathrm{pa}}(\%)$ & 3.2 & 1.6 & 1.5 & 1.9 & 4.8 & 2.3 & 1.6 & 6.4 & 6.5 \\
$\mathbf{P a V}\left(\mathbf{m m}^{3}\right)$ & 874 & 437 & 409 & 519 & 1310 & 628 & 437 & 1747 & 1774 \\
$\% \mathbf{V}_{\mathbf{0}}$ & 14.3 & 10.9 & 11.0 & 10.8 & 24.5 & 21.1 & 7.5 & 27.0 & 28.1
\end{tabular}

$\mathrm{P}_{\mathrm{pa}}(\%)$ : porosity considering pores occupied by paraffin wax; $\mathrm{PaV}$ : paraffin wax volume inside the samples; \% $\mathrm{V}_{0}$ : percentage of the volume of pores occupied by the paraffin wax 
Table 4. Morphological characteristics of the pores filled with paraffin wax larger than $0.2 \mathrm{~mm}^{3}$

\begin{tabular}{cccccccccc}
\hline Sample & $\mathbf{S 1}$ & $\mathbf{S 2}$ & $\mathbf{S 3}$ & $\mathbf{S 4}$ & $\mathbf{S 5}$ & $\mathbf{S 6}$ & $\mathbf{S 7}$ & $\mathbf{S 8}$ & $\mathbf{S 9}$ \\
\hline $\mathbf{P}_{\mathbf{p a}}(\%)$ & 1.9 & 1.1 & 0.7 & 0.8 & 3.9 & 1.6 & 0.9 & 6.1 & 6.2 \\
$\mathbf{P a V}\left(\mathbf{m m}^{3}\right)$ & 510 & 286 & 180 & 227 & 1073 & 444 & 253 & 1671 & 1680 \\
$\mathbf{N P}_{\mathbf{p a}}$ & 361 & 127 & 185 & 246 & 238 & 242 & 118 & 59 & 85 \\
\hline $\mathrm{NP}$
\end{tabular}

$\mathrm{NP}_{\mathrm{pa}}$ : number of pores with paraffin

Table 5. Soil bulk density measured by the core and paraffin-coated methods

\begin{tabular}{|c|c|c|}
\hline \multirow[t]{2}{*}{ Sample type } & No paraffin wax ingress & Paraffin wax ingress \\
\hline & \multicolumn{2}{|c|}{ BD $\left(\mathrm{g} \mathrm{cm}^{-3}\right)$} \\
\hline Group 1* & $1.30 \mathrm{a}$ & $1.41 \mathrm{~b}$ \\
\hline Group 2** & $1.24 \mathrm{a}$ & $1.33 \mathrm{~b}$ \\
\hline
\end{tabular}

